\title{
Confirmation that Xq27 and Xq28 are susceptibility loci for migraine in independent pedigrees
}

and a case-control cohort

Maher B.H. ${ }^{1}$, Kerr M. ${ }^{1}$, Cox, H.C. ${ }^{1}$, MacMillan J.C. ${ }^{2}$, Brimage P.J. ${ }^{3}$, Esposito T. ${ }^{4}$, Gianfrancesco F. ${ }^{4}$, Haupt L.M. ${ }^{1}$, Nyholt D. ${ }^{5}$, Lea, R.A. ${ }^{1}$, Griffiths L.R. ${ }^{1}$

${ }^{1}$ Genomics Research Centre, School of Medical Science, Griffith Health Institute, Griffith University, Gold Coast, Queensland, Australia, ${ }^{2}$ Queensland Clinical Genetics Service, Royal Children's Hospital, Herston, Brisbane, Australia,

${ }^{3}$ Institute of Neurological Sciences, Prince of Wales Hospital, New South Wales, Australia

${ }^{4}$ Institute of Genetics and Biophysics, Italian National Research Council, Naples, Italy

${ }^{5}$ Neurogenetics Laboratory, Queensland Institute of Medical Research, Brisbane, Queensland, Australia,

\section{Corresponding author:}

Professor Lyn Griffiths

e-mail: 1.griffths@griffth.edu.au

Genomics Research Centre, Griffith Health Institute,

Griffith University, Queensland 4222, Australia.

t: +61755528664

f: +61 755529081 


\begin{abstract}
Background: Migraine is a complex neurological disorder that is characterised by debilitating headache and temporary neurological disturbances. Investigations into migraine genetics have also shown that male probands have a higher proportion of affected first degree relatives and migraine has a female preponderance of 3:1. These findings collectively indicate that an X-linked dominant form of inheritance may be playing a role in migraine.
\end{abstract}

Methods: We have previously implicated the $\mathrm{Xq} 24-28$ locus in migraine using 2 independent multigenerational Australian pedigrees that demonstrated excess allele sharing at the Xq24, Xq27 and Xq28 loci. Here, we expand this work to investigate a further 6 independent migraine pedigrees using 11 microsatellite markers spanning the Xq27-28 region. Furthermore, 11 candidate genes are investigated in an Australian case-control cohort consisting of 500 cases and 500 controls.

Results: Microsatellite analysis showed evidence of excess allele sharing to the Xq27 marker DXS8043 (LOD* 1.38 p=0.005) in MF879 whilst a second independent pedigree showed excess allele sharing to DXS8061 at Xq28 (LOD* $1.5 \mathrm{p}=0.004)$. Furthermore, analysis of these key markers in a case control cohort showed significant association to migraine in females at the DXS8043 marker (T1 $\mathrm{P}=0.009)$ and association with MO at DXS8061 (T1 P=0.05). Further analysis of 11 key genes across these regions showed significant association of a 3 marker risk haplotype in the NSDHL gene at Xq28 $(\mathrm{P}=0.0082)$.

Conclusion: The results of this study, combined with previous evidence supporting an X-linked mode of inheritance suggest that susceptibility loci influencing migraine exist independently on Xq27 and $\mathrm{Xq} 28$ and SNP haplotype analyses indicate the Xq28 causative factor is relatively common in the general population. The NSDHL and $C N G A 2$ genes should also be further investigated to elucidate their functional implications in this disorder.

\title{
Keywords: Migraine, MA, MO, X-linked
}




\section{Introduction}

Migraine is a common episodic disorder displaying a complex aetiology which is often inherited in families. The disorder affects approximately $18 \%$ of adult females and $6 \%$ of adult males globally [1,2]. Migraine is characterised by recurrent headache and neurological disturbances such as photophobia and phonophobia. Numerous studies have demonstrated the genetic contribution to migraine through pedigree and twin studies with heritability estimates ranging between 34 and $57 \%$ [3].

Genetic studies have identified three ion channel genes that independently cause the rare migraine subtype Familial Hemiplegic Migraine (FHM) [4-6]. However, identification of genes contributing to the common forms of migraine; Migraine with (MA) or without (MO) Aura, have been more difficult. Genes that have been implicated in MA and/or MO include hormone receptors (Estrogen [7] and Progesterone [8]), serotonin genes [9-11], Dopamine Beta Hydroxylase [12,13] and the KCNK18 gene encoding the TRESK potassium channel [14] among others. Despite these efforts by our group and others, it is still unknown how many genes may be interacting and contributing to common migraine pathogenesis. The focus in present genetic research largely centres on neurological, vascular or hormonal genes based on the current understanding of migraine pathophysiology.

Linkage studies have also been used to identify a number of migraine susceptibility loci on various chromosomes. Results from our laboratory have implicated 1q31 [15]; 3qter, 18p11 [16]; 19p13 [17] and the Xq24-28 locus [18,19] in Australian migraine pedigrees. Others have also identified 2 independent loci on chromosomes 4; 4q21 using Icelandic pedigrees [20] and 4q24 in Finnish pedigrees [21]; as well as 5q21 using studies of Australian twins [22]; 6p12.2-21.1 in a Swedish pedigree [23] and 15q11-q13 [24]. Susceptibility loci have also been identified on 10q22-23 [25,26,22], $18 \mathrm{q} 12[25,26,20]$ and Xp22 [26,27] using traditional migraine classification methods as well as trait component analysis or latent class analysis. However, the majority of these susceptibility loci have not been confirmed in independent populations and many are yet to have susceptibility genes identified within them. This lack of consensus in identification of susceptibility loci and genes highlights the likely heterogeneity of this disorder. 
Due to the genetic heterogeneity the mode of transmission of migraine remains largely unclear. The biased preponderance of migraine in women, as well as studies that demonstrate that a high proportion of affected males have a greater number of affected first degree relatives [28] suggests an X-linked dominant form of migraine inheritance. Families transmitting migraine through this mode of inheritance would show father to daughter transmission and an absence of father to son transmission. Therefore an excess of affected females is likely to be observed within these families.

The X chromosome has been previously identified by our laboratory as potentially harbouring a susceptibility locus at Xq24-28 [18,17]. Studies of two Australian pedigrees identified three specific loci with excess allele sharing in the region. The first was at Xq24 between markers DXS1001 and DXS1206, a second at Xq27 between markers DXS984-DXS1123, and the third at Xq28 between marker DXS8091 and XqTer. The Xq24 locus contains the candidate gene GRIA3 which has been investigated and results described elsewhere [29]. In this study we sought to further investigate the $\mathrm{Xq} 27$ and $\mathrm{Xq} 28$ locus through studies of six new independent Australian migraine pedigrees as well as candidate gene studies in an Australian case control cohort.

\section{Materials and Methods:}

\section{Pedigree Study}

Pedigree Collection and Phenotyping

This study examined 8 Australian Caucasian pedigrees, six new pedigrees designated MF6, MF47, MF55, MF541, MF878 and MF879, as well as the previously reported pedigrees MF7 and MF14 $[18,19]$. These pedigrees include 161 individuals for whom DNA was available. Ethical clearance was granted prior to the commencement of the study by the Griffith University Human Research Ethics Committee. All participants signed informed consent statements prior to inclusion in the study and were interviewed by a clinical neurologist. Individuals were diagnosed for migraine (MA or MO) according to International Headache Society (IHS) criteria [30]. A questionnaire was used to obtain specific information from study participants on a number of relevant factors including age of onset, frequency, duration, associated symptoms, medication response and triggers in accordance with IHS 
guidelines. A total of 96 individuals were classified as affected. Venous blood was collected from participants and DNA was isolated from lymphocytes using a standard salting out procedure [31].

\section{Pedigree Genotyping}

Eleven dinucleotide microsatellite markers were tested in this study. Nine of the 11 markers were examined in the initial study to identify this locus and were therefore repeated in the new pedigrees for consistency. The additional 2 markers, DXS8043 and DXS1073, were used to aid in finemapping the identified region.

Marker order and positions were acquired from Duffy's interpolated Rutgers Map [32] with markers spaced approximately $5.5 \mathrm{cM}$ apart spanning a $66 \mathrm{cM}$ region. Marker names and cumulative positions in Kosambi centimorgans (cM) are:

DXS1206 (0.0) - DXS984 (13.8) - DXS8106 (23.39) - DXS8043 (28.6) - DXS297 (32.8) - DXS8091 (35.54) - DXS1123 (37.22) - DXS8061 (47.68) - DXS15 (48.24) - DXS1073 (51.09) - DXS1108 $(51.57)$

Microsatellites were amplified using standard PCR with 5' labelled forward primers where the labels were either FAM, PET, NED or VIC. Primer sequences are given in Online Resource 1 and PCR conditions are available on request. Where possible, due to overlapping fragment size and limited labels, PCR products were multiplexed before sizing by capillary electrophoresis using the Applied Biosystems ABI 3130 Genetic Analyser. Genotypes were called using the Applied Biosystems GENEMAPPER® software Version 4.0.

\section{Statistical Analysis of Pedigrees}

Prior to statistical analysis genotype data was screened for mendelian and relationship inconsistencies using Pedcheck [33]. Error checking was also performed in the MINX program and unlikely genotypes were resolved or removed. The Kong and Cox GENEHUNTER PLUS (X-Linkage version 1.2) statistical software [34] was used to carry out non-parametric multipoint linkage analysis of these pedigrees using the $S_{\text {all }}$ scoring function. Non-parametric analysis was chosen to overcome difficulties 
in defining unknown inheritance parameters. The $\mathrm{S}_{\text {all }}$ statistic was chosen as it measures IBD allele sharing among all individuals simultaneously rather then pairs of affected relatives therefore assigning a higher score as more individuals share the same allele by descent. The LOD* scores were determined implementing the exponential model. Previously reported pedigrees MF7 and MF14 were reanalysed with additional makers and an updated marker map. Linkage peaks yielding LOD* scores $\geq 1$ are suggestive of linkage for $\mathrm{X}$ chromosome markers whilst LOD* scores $\geq 2$ indicate significant linkage. LOD scores were converted to $\mathrm{P}$ values using the ConvertingLODtoPvalue spreadsheet [35]. Haplotypes were determined from genotype and pedigree information using the X-linked version of Merlin, Minx [36] and diagrams were created using the Haplopainter program [37] .

\section{Association study \\ Population Collection and Phenotyping}

The study protocol was approved by Griffith University's ethics committee for experimentation on humans. All individuals were of Caucasian origin and gave informed consent before participating in the research. Migraineurs were diagnosed as having either MA or MO, based strictly on criteria specified by the IHS. All individuals were grouped together and phenotyped as being affected with typical migraine, as well as being diagnosed separately as MA or MO subgroups. The case-control study cohort was comprised of 500 migraineurs (360 MA/140 MO; 393 Female/107 Male) and 500 unrelated control individuals. To minimise potential bias from population stratification, the control group was matched for sex, age (+/- 5 years) and ethnicity to the migraineurs.

\section{Microsatellite Markers}

Two key microsatellite markers identified in the Xq27 (DXS8043) and Xq28 (DXS8061) loci were genotyped in the association study population to determine if the association was pedigree specific or could translate to the general population. Genotyping was carried out using the same process described for the pedigree study. 


\section{Candidate Gene Studies}

A gene map of the Xq27 and Xq28 regions were obtained from NCBI (Homo sapiens Genome Build 37.2) and public databases (eg. Pubmed) were interrogated for functional gene information in order to select a final list of 2 genes in the Xq27 locus and 10 genes in the Xq28 locus (Online Resource 2).

Hapmap CEU data was downloaded for each candidate gene and the tagger algorithm in Haploview [38] was used to identify 36 SNPs across 11 of the 12 genes that captured the maximum degree of variation attainable while being constrained by multiplexing genotyping techniques. Of the polymorphisms genotyped across the 2 regions, 1 is an insertion/deletion polymorphism in GPR50 amplified using standard PCR with 5' FAM labelled forward primer (Online Resource 1). PCR conditions are available on request. Genotypes were determined by capillary electrophoresis using the Applied Biosystems ABI 3130 Genetic Analyser. Genotypes were called using the Applied Biosystems GENEMAPPER ${ }^{\circledR}$ software Version 4.0. The remaining 35 SNPs were genotyped at Australian Genome Research Facility (AGRF) using the Sequenom MassArray on an Autoflex Spectrometer and iPLEX GOLD chemistry.

\section{Statistical Analysis of case-control cohort}

Microsatellites were tested for association using the CLUMP analysis program [39]. To detect association between the SNP markers and migraine, we performed chi-square $\left(\chi^{2}\right)$ analysis to test for significant differences in allele and genotype frequencies (females only for associated SNPs) in case versus control results. $\chi^{2}$ provides the likelihood of a deviation in the distribution of the same attributes in different classes (e.g. allelic frequencies in controls versus affected subjects). Hardy-Weinberg Equilibrium (HWE) for females control genotypes were also calculated using PLINK [40]. For the candidate gene study locus-specific correction set the significance level at 0.008 for Xq27 and 0.001 for Xq28. Haplotype frequency estimates and analysis of the haplotype block consisting of markers rs5970389, rs6653488 and rs2071256 in the MO and control cohorts were performed using Haploview [41].

\section{Results:}


The current study presents an analysis of the previously identified migraine susceptibility locus, Xq27 Xq28, using six new multigenerational Australian migraine pedigrees. In addition two of these markers were also analysed in a case-control migraine cohort to investigate this signal in a general migraine population. Finally, this study also interrogates a number of candidate genes within the identified susceptibility region.

\section{Pedigree analysis}

We reported previously the identification of a migraine susceptibility locus on chromosome Xq24-28 $[18,19]$. Significant excess allele sharing was indicated by nonparametric linkage analysis producing maximum global LOD* scores of 2.31 between DXS8106 and DXS091; and LOD* 2.18 at DXS8061.

For the present study, we included new and combined analysis of the two previously published pedigrees and six new migraine pedigrees confirming the excess allele-sharing across this region. Analysis was performed in the pedigrees with individuals classed as affected, unaffected or unknown, combining the MA and MO phenotypes as a spectrum of the migraine disorder. An analysis was also undertaken with individuals classed as either unknown or affected in case migraine had not manifested in the individual due to a lack of environmental triggers. However, this analysis did not significantly vary the outcome and therefore results are not included.

Analysis of the pedigrees verified and refined the previously localised susceptibility regions. Migraine pedigrees MF6, MF55, MF541 and MF878 did not show evidence of excess allele sharing to the Xq2728 region (data not shown). However, analysis of the remaining migraine families confirmed the previous observation at Xq27 and Xq28 (Figure 1). At the Xq27 loci maximum LOD* scores of 1.32 $(\mathrm{P}=0.0068), 1.35(\mathrm{P}=0.0063)$ and $1.38(\mathrm{P}=0.0058)$ were identified for MF7, MF14 and MF879 respectively. Similarly at the Xq28 locus maximum LOD* scores of 1.33-1.50 spanned the locus from DXS8061 to the final marker DXS1108 in MF7, MF14 and MF47 (Figure 1).

An initial global scan of all migraine families included in the study was suggestive of linkage across $\mathrm{Xq} 27$ and $\mathrm{Xq} 28$ with maximum LOD* scores peaking at $1.63(\mathrm{P}=0.003)$ at DXS8043 (Figure 1). To 
determine the effect the 4 families that did not show excess allele sharing to the Xq27 or Xq28 region were having on this result a further analysis was conducted removing these families (Figure 1).

Previous analysis of MF7 and MF14 has also shown evidence to support genetic heterogeneity of the disorder in these families [18] potentially suggesting that 2 independent loci exist in this region. Analysis of the new migraine families supports this theory as the individual analysis of MF879 only shows excess allele sharing at Xq27 and conversely MF47 only shows excess allele sharing at Xq28. A global analysis was therefore performed on each region using only those pedigrees that implicated the respective loci in order to refine the linkage regions for further analysis. This analysis revealed a maximum global LOD score of $3.69\left(\mathrm{P}=1.88 \times 10^{-5}\right)$ between markers DXS8043 and DXS297 at Xq27 for the combined analysis of MF7, MF14 and MF879. At Xq28 the combined analysis of MF7, MF14 and MF47 showed a LOD* of $3.65\left(\mathrm{P}=2.07 \times 10^{-5}\right)$ at $\mathrm{DXS} 8061$.

Haplotype analysis confirmed a narrowed Xq27 region from the previous study through critical recombination events in the new MF879 pedigree. Individuals IV:4 and IV:5 in MF879 show recombination at DXS8043xDXS297, the markers that bound the Xq27 locus, suggesting that a susceptibility candidate in this region is between these markers (Figure 2). While the new pedigree MF47 was also shown to display excess allele sharing to the Xq28 region, haplotype analysis did not narrow the region that was identified previously [18].

The Xq27 region implicated by these studies are bordered by markers DXS8043 and DXS297 translating to at most a $2.4 \mathrm{Mb}$ region. Similarly the Xq28 region is limited by DXS8061 to the Xqter equating to an approximate $4 \mathrm{Mb}$ region.

\section{Investigation of key microsatellite markers in a case-control cohort}

In order to test if the signals identified at the Xq27 and Xq28 loci were pedigree specific or translated to the general population two key microsatellite markers in the regions were genotyped in an Australian migraine case control cohort. The markers DXS8043 and DXS8061 (Xq27 and Xq28 respectively) showed evidence of association in the tested female population ( $\mathrm{P}=0.009$ and $\mathrm{P}=0.07$ respectively). 
While DXS8043 appears not to be specific to a particular migraine subtype, DXS8061 is clearly associated with the MO class $(\mathrm{P}=0.05$, Table 1$)$.

A SNP in close proximity to each marker was also genotyped in this population to verify the association seen by the microsatellites. rs5920369 located 720bp upstream to DXS8043 confirmed the association to the female population (genotype $\mathrm{P}=0.01$ ). While rs6653488, $2.8 \mathrm{~Kb}$ from DXS8061 also showed association to females $(\mathrm{P}=0.02)$.

\section{Xq27 Candidate Gene Study}

Interrogation of public databases for gene annotations in the $\sim 2.4 \mathrm{Mb} \mathrm{Xq} 27$ loci bordered by markers DXS8043 and DXS297 identified very few known genes. Consequently only 2 candidate genes were selected for further analysis, SLITRK2 and CXorf1 (see Online Resource 2). Four SNPs were identified for analysis across these 2 genes. All SNPs were in HWE however none showed association.

\section{Xq28 Candidate Gene Study}

In contrast to the $\mathrm{Xq} 27$ locus the $\mathrm{Xq} 28$ region harbours numerous potential candidate genes. In this region 29 SNPs were chosen across 9 candidate genes. These genes were selected based on known or implied functional roles in hormonal, vascular or neurological systems (see Online Resource 2).

One SNP was found to be in HWD $(\mathrm{P}<0.001)$ and was not used for further studies. Chi square analysis identified a SNP in $C N G A 2$ with positive association, $\mathrm{P}=0.048$, which was also stronger in females (genotype $\mathrm{P}=0.0038$ ) when analysed by gender, however this did not remain significant after corrections. No other SNPs were associated in the entire cohort or when stratified by gender.

However to further investigate the association to MO observed at the microsatellite marker DXS8061, the SNPs around this marker were also tested for association to this migraine class. This analysis identified 3 SNPs around the DXS8061 marker that independently showed a trend towards association with MO $(\mathrm{P} \leq 0.07)$. Haplotype analysis of this series of SNPs revealed a 3 marker risk haplotype at rs5970389, rs6653488 and rs2071256 $(\mathrm{P}=0.0082, \mathrm{OR}=1.53 \mathrm{CI}=1.11-2.11)$ in the NSDHL gene (Table 2). 


\section{Discussion:}

The genetic basis of common migraine, MA and MO is yet to be deciphered. To date, loci on many chromosomes as well as a number of genes have been implicated yet we still lack replication studies to validate these findings. Furthermore, the current understanding of migraine pathophysiology is fragmented with the vascular, hormonal and neural systems all thought to play a role.

The unequal sex distribution in the general population strongly implicates a hormonal influence on migraine pathophysiology. Epidemiological data supports this as prevalence significantly increases in females at the time of puberty and decreases around the time of menopause [42]. Furthermore, 7-8\% of migraineurs experience the ICHD classified, Pure Menstrual Migraine, where MO occurs only on day $1 \pm 2$ days of menstruation in every 2 of 3 cycles. While it is not specifically known how hormones contribute to migraine it has been demonstrated that some hormones, particularly estrogen, interact with other genes that have been implicated in migraine such as serotonin receptors and calcitonin gene related peptide $(C G R P)$ [43]. However to date studies of these genes have failed to provide conclusive evidence that hormones are the sole factor causing the female preponderance of migraine. It is therefore a distinct possibility that genes on the $\mathrm{X}$ chromosome may also be contributing to susceptibility to the disorder.

In this study we have expanded on previous work to narrow known susceptibility regions on the $\mathrm{X}$ chromosome in order to reduce the number of potential candidate genes for testing in common migraine. The initial scan by this laboratory was performed using 28 markers across the $\mathrm{X}$ chromosome in two Australian pedigrees. Results demonstrated significant NPL scores at markers DXS1001 (Xq24) and DXS1123 (Xq28) [19]. A follow-up study of these two pedigrees focused on the Xq region using 16 markers that identified three distinct loci. The first was at Xq24 spanning from markers DXS1001 to DXS1206 the second was at Xq27 from markers DXS984 to DXS1123 and the third at Xq28 from DXS8091 to XqTer [18]. 
Here, we expand on these findings in 6 new Australian migraine pedigrees. In the initial study the Xq27 locus was identified as spanning an 11Mb region from markers DXS984 to DXS1123. Through genotyping of an additional marker in this region (DXS8043) we have reduced the locus shared by 3 pedigrees to a $2.4 \mathrm{Mb}$ region, assuming that all pedigrees are segregating to the same susceptibility gene. In addition the genotyping of additional migraine pedigrees has identified 2 previously unreported pedigrees that segregate to the 2 susceptibility regions strongly confirming a role for the $\mathrm{X}$ chromosomes in migraine.

This study also provides further evidence to indicate that the identified regions can be considered two separate loci, independently harbouring susceptibility variants. While MF7 and MF14 show excess allele sharing at both regions MF879 only associated with the Xq27 locus, similarly MF47 only associated with the Xq28 locus. In addition, the Xq27 locus has now been identified in three separate studies. Oedegaard and colleagues [44] conducted a genome wide linkage study of bi-polar disorder and co-morbid migraine using pedigrees derived from the National Institute of Mental Health (NIMH) Genetics Initiative for Bipolar Disorder. They identified a linkage peak with a LOD score of 1.6 $(\mathrm{P}=0.003)$ in the Xq27 region (marker DXS9908 approx 1Mb from DXS8043) that segregated with only the migraine and not the bipolar phenotype.

Our finding that the key markers identifying the $\mathrm{X}$ chromosome susceptibility regions are also associated in a case-control population provides evidence that these loci are not pedigree specific and may be contributing to migraine in the general population. This result provides the impetus to identify the causative variants through candidate gene studies.

The Xq27 loci appears to be a particularly 'gene poor' region. To date few annotations in this region are available on public databases. Consequently only 2 genes (SLITRK2 and CXorf1) were examined in the region with neither showing association.

In contrast the $\mathrm{Xq} 28$ region contains numerous potential candidate genes such as the neurotransmitter genes SLC6A8, GABRE, GABR3 and GABRQ and ion channel genes CLIC2 and CNGA2. In particular GABRA3 was of interest due to the plethora of evidence implicating a role for glutamate in migraine 
particularly in increasing susceptibility to cortical spreading depression [45,46]. The GABRE and $G A B R Q$ genes located in the $\mathrm{Xq} 28$ region were not selected as these have been analysed and reported previously as showing no association to migraine in our Australian populations [47]. The ATP2B3 gene was also selected as this gene belongs to the ATPase family similar to the FHM2 gene ATP1A2, and furthermore, $A T P 2 B 3$ is thought to play a role in calcium homeostasis as does the FHM1 gene CACNA1A. Other genes selected for this study are known ion channels thought to be involved in neurological processes. The ion channel genes were of particular interest as it has been established that FHM can be caused by independent mutations in three different ion channels. Additionally ion channels may play a role in neuronal excitability, potentially contributing to the precipitation of migraine attack.

While this study did not strongly implicate any of the tested genes in migraine, suggestive evidence of a 3 marker haplotype in the MO subtype may be seen in the NSDHL gene. This gene is involved in the synthesis of cholesterol and loss-of-function mutations are typically associated with CHILD syndrome, a severe disorder that is lethal in males. However numerous studies have linked CVD with migraine and some studies suggest an influence of cholesterol levels on both disorders [48-50]. Nonetheless the results of this study nominally suggest an involvement of $N S D H L$ in migraine, therefore if this gene is involved, significant further research into the functional implications of genetic variants in this gene need to be investigated.

\section{Conclusion:}

The unequal sex distribution of migraine is a unique facet of this disorder that may be explained by hormones and/or underlying genetic variations on the $\mathrm{X}$ chromosome that potentially cause migraine predisposition. The polygenic nature of migraine suggests that an interaction of both these mechanisms is also a possibility. The results of this study suggest that 2 distinct susceptibility variants may exist at Xq27 (marked by DXS8043 - DXS297) and Xq28 (DXS8061 - XqTer) and that these susceptibility loci may extend to association in the general population. Further studies are warranted to identify the pathological relevance of these loci to migraine aetiology.

\section{Acknowledgements:}


This research was supported by funding an Australian DEST International Science Linkages grant. Bridget Maher was supported by an Australian Postgraduate Award Scholarship and Rod Lea is partially supported by a Corbett Research Fellowship.

\section{Conflict of Interest:}

The authors declare that they have no conflict of interest

\section{Ethical Standards:}

All experiments comply with the current laws of Australia 
Table 1: Microsatellite analysis in case-control cohort

\begin{tabular}{|c|c|c|c|c|c|c|c|}
\hline \multirow[t]{2}{*}{ Marker } & \multirow[t]{2}{*}{ Position } & \multirow[t]{2}{*}{ Locus } & \multicolumn{5}{|c|}{ CLUMP analysis $P$ value } \\
\hline & & & $\begin{array}{l}\text { Cases v } \\
\text { Controls }\end{array}$ & $\begin{array}{l}\text { MA v } \\
\text { Controls }\end{array}$ & $\begin{array}{l}\text { MO v } \\
\text { Controls }\end{array}$ & $\begin{array}{l}\text { Male v } \\
\text { Controls }\end{array}$ & $\begin{array}{l}\text { Female v } \\
\text { Controls }\end{array}$ \\
\hline DXS8043 & 143836250 & $\mathrm{Xq} 27$ & & & & & \\
\hline & & & 0.014 & 0.019 & 0.012 & 0.7 & 0.009 \\
\hline DXS8061 & 151772260 & $\mathrm{Xq} 28$ & 0.25 & 0.5 & 0.05 & 0.61 & 0.07 \\
\hline
\end{tabular}

Table 2: Xq28 MO Risk Haplotype rs5970389, rs6653488 and rs2071256

\begin{tabular}{lllllll}
\hline Haplotype & Freq (MO) & Freq (Cases) & $\chi 2$ & P & OR & $95 \%$ CI \\
\hline TTC & 0.689 & 0.591 & 6.997 & 0.0082 & 1.53 & $1.11-2.11$ \\
CCG & 0.148 & 0.229 & 6.687 & 0.0097 & 0.58 & $0.38-0.88$ \\
CTG & 0.112 & 0.12 & 0.0105 & 0.7464 & 0.92 & $0.57-1.48$ \\
TTG & 0.035 & 0.051 & 0.867 & 0.3518 & 0.69 & $0.31-1.51$ \\
\hline
\end{tabular}




\section{References}

1. Lipton RB, Bigal ME, Diamond M, Freitag F, Reed ML, Stewart WF (2007) Migraine prevalence, disease burden, and the need for preventive therapy. Neurology 68 (5):343-349.

2. Stovner LJ, Zwart JA, Hagen K, Terwindt GM, Pascual J (2006) Epidemiology of headache in Europe. Eur J Neurol 13 (4):333-345

3. Mulder EJ, Van Baal C, Gaist D, Kallela M, Kaprio J, Svensson DA, Nyholt DR, Martin NG, MacGregor AJ, Cherkas LF, Boomsma DI, Palotie A (2003) Genetic and environmental influences on migraine: a twin study across six countries. Twin Res 6 (5):422-431.

4. De Fusco M, Marconi R, Silvestri L, Atorino L, Rampoldi L, Morgante L, Ballabio A, Aridon P, Casari G (2003) Haploinsufficiency of ATP1A2 encoding the Na+/K+ pump alpha2 subunit associated with familial hemiplegic migraine type 2. Nat Genet 33 (2):192-196.

5. Dichgans M, Freilinger T, Eckstein G, Babini E, Lorenz-Depiereux B, Biskup S, Ferrari MD, Herzog J, van den Maagdenberg AM, Pusch M, Strom TM (2005) Mutation in the neuronal voltagegated sodium channel SCN1A in familial hemiplegic migraine. Lancet 366 (9483):371-377.

6. Ophoff RA, Terwindt GM, Vergouwe MN, van Eijk R, Oefner PJ, Hoffman SM, Lamerdin JE, Mohrenweiser HW, Bulman DE, Ferrari M, Haan J, Lindhout D, van Ommen GJ, Hofker MH, Ferrari MD, Frants RR (1996) Familial hemiplegic migraine and episodic ataxia type-2 are caused by mutations in the Ca2+ channel gene CACNL1A4. Cell 87 (3):543-552.

7. Colson NJ, Lea RA, Quinlan S, Griffiths LR (2006) No role for estrogen receptor 1 gene intron 1 Pvu II and exon 4 C325G polymorphisms in migraine susceptibility. BMC Med Genet 7:12.

8. Colson NJ, Lea RA, Quinlan S, MacMillan J, Griffiths LR (2005) Investigation of hormone receptor genes in migraine. Neurogenetics 6 (1):17-23.

9. Erdal ME, Herken H, Yilmaz M, Bayazit YA (2001) Association of the T102C polymorphism of 5HT2A receptor gene with aura in migraine. J Neurol Sci 188 (1-2):99-101.

10. Ogilvie AD, Russell MB, Dhall P, Battersby S, Ulrich V, Smith CA, Goodwin GM, Harmar AJ, Olesen J (1998) Altered allelic distributions of the serotonin transporter gene in migraine without aura and migraine with aura. Cephalalgia 18 (1):23-26

11. Yilmaz M, Erdal ME, Herken H, Cataloluk O, Barlas O, Bayazit YA (2001) Significance of serotonin transporter gene polymorphism in migraine. J Neurol Sci 186 (1-2):27-30.

12. Fernandez F, Colson N, Quinlan S, MacMillan J, Lea RA, Griffiths LR (2009) Association between migraine and a functional polymorphism at the dopamine beta-hydroxylase locus. Neurogenetics 10 (3):199-208

13. Lea RA, Dohy A, Jordan K, Quinlan S, Brimage PJ, Griffiths LR (2000) Evidence for allelic association of the dopamine beta-hydroxylase gene (DBH) with susceptibility to typical migraine. Neurogenetics 3 (1):35-40

14. Lafreniere RG, Cader MZ, Poulin JF, Andres-Enguix I, Simoneau M, Gupta N, Boisvert K, Lafreniere F, McLaughlan S, Dube MP, Marcinkiewicz MM, Ramagopalan S, Ansorge O, Brais B, Sequeiros J, Pereira-Monteiro JM, Griffiths LR, Tucker SJ, Ebers G, Rouleau GA (2010) A dominantnegative mutation in the TRESK potassium channel is linked to familial migraine with aura. Nat Med. 
15. Lea RA, Shepherd AG, Curtain RP, Nyholt DR, Quinlan S, Brimage PJ, Griffiths LR (2002) A typical migraine susceptibility region localizes to chromosome 1q31. Neurogenetics 4 (1):17-22 16. Lea RA, Nyholt DR, Curtain RP, Ovcaric M, Sciascia R, Bellis C, Macmillan J, Quinlan S, Gibson RA, McCarthy LC, Riley JH, Smithies YJ, Kinrade S, Griffiths LR (2005) A genome-wide scan provides evidence for loci influencing a severe heritable form of common migraine. Neurogenetics 6 (2):67-72.

17. Nyholt DR, Lea RA, Goadsby PJ, Brimage PJ, Griffiths LR (1998) Familial typical migraine: linkage to chromosome 19p13 and evidence for genetic heterogeneity. Neurology 50 (5):1428-1432

18. Nyholt DR, Curtain RP, Griffiths LR (2000) Familial typical migraine: significant linkage and localization of a gene to Xq24-28. Hum Genet 107 (1):18-23

19. Nyholt DR, Dawkins JL, Brimage PJ, Goadsby PJ, Nicholson GA, Griffiths LR (1998) Evidence for an X-linked genetic component in familial typical migraine. Hum Mol Genet 7 (3):459-463.

20. Bjornsson A, Gudmundsson G, Gudfinnsson E, Hrafnsdottir M, Benedikz J, Skuladottir S, Kristjansson K, Frigge ML, Kong A, Stefansson K, Gulcher JR (2003) Localization of a gene for migraine without aura to chromosome 4q21. Am J Hum Genet 73 (5):986-993.

21. Wessman M, Kallela M, Kaunisto MA, Marttila P, Sobel E, Hartiala J, Oswell G, Leal SM, Papp JC, Hamalainen E, Broas P, Joslyn G, Hovatta I, Hiekkalinna T, Kaprio J, Ott J, Cantor RM, Zwart JA, Ilmavirta M, Havanka H, Farkkila M, Peltonen L, Palotie A (2002) A susceptibility locus for migraine with aura, on chromosome 4q24. Am J Hum Genet 70 (3):652-662.

22. Nyholt DR, Morley KI, Ferreira MA, Medland SE, Boomsma DI, Heath AC, Merikangas KR, Montgomery GW, Martin NG (2005) Genomewide significant linkage to migrainous headache on chromosome 5q21. Am J Hum Genet 77 (3):500-512.

23. Carlsson A, Forsgren L, Nylander PO, Hellman U, Forsman-Semb K, Holmgren G, Holmberg D, Holmberg M (2002) Identification of a susceptibility locus for migraine with and without aura on 6p12.2-p21.1. Neurology 59 (11):1804-1807

24. Russo L, Mariotti P, Sangiorgi E, Giordano T, Ricci I, Lupi F, Chiera R, Guzzetta F, Neri G, Gurrieri F (2005) A new susceptibility locus for migraine with aura in the 15q11-q13 genomic region containing three GABA-A receptor genes. Am J Hum Genet 76 (2):327-333.

25. Anttila V, Kallela M, Oswell G, Kaunisto MA, Nyholt DR, Hamalainen E, Havanka H, Ilmavirta M, Terwilliger J, Sobel E, Peltonen L, Kaprio J, Farkkila M, Wessman M, Palotie A (2006) Trait components provide tools to dissect the genetic susceptibility of migraine. Am J Hum Genet 79 (1):8599.

26. Anttila V, Nyholt DR, Kallela M, Artto V, Vepsalainen S, Jakkula E, Wennerstrom A, TikkaKleemola P, Kaunisto MA, Hamalainen E, Widen E, Terwilliger J, Merikangas K, Montgomery GW, Martin NG, Daly M, Kaprio J, Peltonen L, Farkkila M, Wessman M, Palotie A (2008) Consistently replicating locus linked to migraine on 10q22-q23. Am J Hum Genet 82 (5):1051-1063.

27. Wieser T, Pascual J, Oterino A, Soso M, Barmada M, Gardner KL (2010) A novel locus for familial migraine on Xp22. Headache 50 (6):955-962.

28. Stewart WF, Staffa J, Lipton RB, Ottman R (1997) Familial risk of migraine: a population-based study. Ann Neurol 41 (2):166-172. 
29. Formicola D, Aloia A, Sampaolo S, Farina O, Diodato D, Griffiths LR, Gianfrancesco F, Di Iorio G, Esposito T (2010) Common variants in the regulative regions of GRIA1 and GRIA3 receptor genes are associated with migraine susceptibility. BMC Med Genet 11:103.

30. IHS (2004) The International Classification of the Headache Disorders 2nd ed. Cephalalgia 24(Suppl 1):1-150

31. Miller S.A DDD, Polesky H.F (1988) A simple salting out procedure for extracting DNA from Human Nucleated cells. Nucleic Acid Reseach 16 (3):1215

32. Duffy DL (2006) An Integrated Genetic Map for Linkage Analysis. Behavior Genetics 36 (1).

33. O'Connell JR, Weeks DE (1998) PedCheck: a program for identification of genotype incompatibilities in linkage analysis. Am J Hum Genet 63 (1):259-266.

34. Kong A, Cox NJ (1997) Allele-sharing models: LOD scores and accurate linkage tests. Am J Hum Genet 61 (5):1179-1188.

35. Nyholt DR (2000) All LODs are not created equal. Am J Hum Genet 67 (2):282-288.

36. Abecasis GR, Cherny SS, Cookson WO, Cardon LR (2002) Merlin--rapid analysis of dense genetic maps using sparse gene flow trees. Nat Genet 30 (1):97-101.

37. Thiele H, Nurnberg P (2005) HaploPainter: a tool for drawing pedigrees with complex haplotypes. Bioinformatics 21 (8):1730-1732.

38. Barrett JC (2009) Haploview: Visualization and analysis of SNP genotype data. Cold Spring Harb Protoc 2009 (10):pdb ip71.

39. Sham PC, Curtis D (1995) Monte Carlo tests for associations between disease and alleles at highly polymorphic loci. Ann Hum Genet 59 (Pt 1):97-105

40. Purcell S, Neale B, Todd-Brown K, Thomas L, Ferreira MA, Bender D, Maller J, Sklar P, de Bakker PI, Daly MJ, Sham PC (2007) PLINK: a tool set for whole-genome association and populationbased linkage analyses. Am J Hum Genet 81 (3):559-575.

41. Barrett JC, Fry B, Maller J, Daly MJ (2005) Haploview: analysis and visualization of LD and haplotype maps. Bioinformatics 21 (2):263-265.

42. Lipton RB, Stewart WF, Diamond S, Diamond ML, Reed M (2001) Prevalence and burden of migraine in the United States: data from the American Migraine Study II. Headache 41 (7):646-657.

43. Gupta S, Mehrotra S, Villalon CM, Perusquia M, Saxena PR, MaassenVanDenBrink A (2007) Potential role of female sex hormones in the pathophysiology of migraine. Pharmacol Ther 113 (2):321-340.

44. Odegaard KJ, Greenwood TA, Lunde A, Fasmer OB, Akiskal HS, Kelsoe JR, Consortium NGIBD (2009) A genome-wide linkage study of bipolar disorder and co-morbid migraine: Replication of migraine linkage on chromosome 4q24, and suggestion of an overlapping susceptibility region for both disorders on chromosome 20p11. J Affect Disord.

45. Jen JC, Wan J, Palos TP, Howard BD, Baloh RW (2005) Mutation in the glutamate transporter EAAT1 causes episodic ataxia, hemiplegia, and seizures. Neurology 65 (4):529-534.

46. Vikelis M, Mitsikostas DD (2007) The role of glutamate and its receptors in migraine. CNS Neurol Disord Drug Targets 6 (4):251-257 
47. Fernandez F, Esposito T, Lea RA, Colson NJ, Ciccodicola A, Gianfrancesco F, Griffiths LR (2008) Investigation of gamma-aminobutyric acid (GABA) A receptors genes and migraine susceptibility. BMC Med Genet 9:109.

48. Bigal ME (2011) Migraine, lipid profile, and cardiovascular disease. Eur J Neurol 17 (3):342-343.

49. Gruber HJ, Bernecker C, Pailer S, Lechner A, Horejsi R, Moller R, Fazekas F, Truschnig-Wilders M (2011) Lipid profile in normal weight migraineurs - evidence for cardiovascular risk. Eur J Neurol 17 (3):419-425.

50. Silberstein SD (2005) Cardiovascular risk factors associated with migraine. Lancet Neurol 4 (7):391-392 . 